\title{
White Coats for Black Lives: Medical Students Responding to Racism and Police Brutality
}

Dorothy Charles, Kathryn Himmelstein, Walker Keenan, and Nicolas Barcelo, for the White Coats for Black Lives National Working Group

KEYWORDS Race, Racism, Police violence, Health disparity, Social justice

JEL CLASSIFICATION 60: Social Factors, 70: Injury/Violence

Last fall, Black people and their allies took to social media and the streets to assert that, despite the non-indictment of officers responsible for the deaths of Michael Brown and Eric Garner, Black lives matter. While these protests sparked national dialogue about racism and violence against communities of color, our medical school campuses remained silent and detached. As medical trainees invested in the lives and well-being of people of color, we felt called to action by the \#BlackLivesMatter movement. Medicine is not immune to the racism that pervades our education, housing, employment, and criminal justice systems. Moreover, racism and police brutality damage the health and lives of people of color, particularly Black people, and must be addressed as a public health crisis.

Initially, students at different medical schools initiated conversations and planned separate actions to engage with larger, national struggles for racial justice. For example, students at the University of California San Francisco, School of Medicine and the Icahn School of Medicine at Mount Sinai independently planned die-in demonstrations regionally and locally, respectively, in solidarity with national die-ins in public spaces. Students at the Perelman School of Medicine at the University of Pennsylvania, who at the time were writing an open letter calling for a public response to racism from medical professionals, heard about the actions being planned at UCSF and Mount Sinai and created a line of communication among the three schools. Students at these schools coordinated a single, national die-in demonstration on December 10, International Human Rights Day.

Through social media, interpersonal connections, and a press release sent out by Physicians for a National Health Program, who endorsed the action, news of the die-in quickly spread nationwide. Ultimately, over 3000 students at more than 80

Charles and Himmelstein are with the Perelman School of Medicine at the University of Pennsylvania, Philadelphia, PA, USA; Keenan and Barcelo are with the School of Medicine, University of California, San Francisco, 1001 Potrero Ave, Bldg 80 W83, San Francisco, CA 94143, USA.

Correspondence: Nicolas Barcelo, School of Medicine, University of California, San Francisco, 1001 Potrero Ave, Bldg 80 W83, San Francisco, CA 94143, USA. (E-mail: nicolas.barcelo@ucsf.edu) 
medical schools across the country participated in the action, demonstrating solidarity with communities protesting against racism and police brutality and publicly stating that health professionals must confront police violence and institutionalized racism. This message was not confined to individual campuses. Under the hashtag \#whitecoats4blacklives, these actions trended on social media and were covered by traditional media, including print, radio, and TV, amplifying our message of solidarity and the call for racial justice in medicine.

Having created a national network of justice-minded medical students, we wanted to build on our classmates' energy around the protests and ensure that \#whitecoats4blacklives was not simply a one-time action but an ongoing movement. Moreover, we wanted to continue to emphasize that the influence granted to physicians should be directed toward social progress for all, particularly to those most affected by racism and burdened by poor health outcomes. We therefore sought to reinvigorate efforts within the medical establishment to promote health equity and support communities of color in their struggles for justice. The national medical student organization, White Coats for Black Lives (WC4BL), was therefore created on Martin Luther King, Jr. Day, 2015, to further these goals.

In founding WC4BL, we identified three key levels on which medical students could promote racial justice. First, we must fight to eliminate racism in housing, criminal justice, education, and other areas as a threat to the lives and well-being of people of color. Second, we must end racial discrimination in the distribution and provision of medical care. Finally, we must demand that our medical schools create a physician workforce that reflects our nation's diversity and is prepared to fight for racial justice.

To accompany these broad areas of work, we have outlined specific goals and action steps. We recognize that discrimination based on insurance status is a mechanism of "color-blind" racial discrimination: while patients cannot legally be denied care because of their race, patients of color are frequently turned away from hospitals because they do not have private health insurance. We therefore support the creation of a single payer health insurance system to ensure that all patients have access to the care they need. To address the underrepresentation of Black, Latino, and Native American people in medicine, we have pushed our schools to create recruitment, retention, and promotion policies that would ensure that people of color are represented among physicians at least at the same rate as they are among the general population. We believe that expanding the use of holistic admissions practices, for example, might increase access to medicine for people of color and enhance the learning environment for all trainees. We have further urged our medical schools to end their overwhelming curricular and research silence on the history of racism in medicine, the role of racism in creating disparate health outcomes, and strategies for physicians to promote racial justice. Finally, we have called on individual physicians, physician organizations, and medical institutions to publicly acknowledge the role of structural racism in damaging the health of their patients of color and to join communities fighting for racial justice.

In the past 4 months, students at medical schools across the country have begun to take action on these goals. Students at dozens of schools, including Case Western, Baylor, and UC San Diego, have facilitated focus groups, "town hall" meetings, and discussions among health professions students and administrators about health and racial justice. These discussions have led to curricular changes and the development of new structures to support the needs of faculty and students of color. Discussions at UCSF, for example, led the administrators to change the theme of the annual 
Dean's retreat to "Race Matters," which highlighted the relevance of race in student and faculty experiences, patient outcomes, and in scientific research. WC4BL also facilitated a photography project featuring portraits of students from Penn, NYU, UCSF, Yale, and Boston University describing what racial justice or equity in medicine meant to them and posted these photographs to social media. Finally, in support of our colleagues at SUNY Downstate, Columbia, and Einstein, the WC4BL National Working Group recently backed and circulated a letter to Surgeon General Vivek Murthy that brought specific attention to the role of structural violence and racism to the health and wellbeing of communities of color.

WC4BL students have also added their voices to public protests against racism, brutality, neglect, and exclusion. Medical students in Baltimore, San Francisco, New York, and Philadelphia joined demonstrations over the police killing of Freddie Gray and other victims of police brutality. In addition to direct actions, students from Brown, Mount Sinai, Creighton, UCSF, and other medical schools have expressed their solidarity and concern through published articles and op-eds responding to incidents of police brutality and the injustices currently plaguing healthcare. Medical student participation in these efforts reflects a variety of motivations. For some, it is a reminder of life before medical school and a motivator to continue training in demanding circumstances. For others, it is an act of humility, an acknowledgement that privilege blinds us to the lives and needs of many of our neighbors and patients.

These organized actions and written pieces have generated discussion on medical campuses about the impact of racism on public health and the presence of racism within our healthcare system. Promoting awareness of these topics is, however, only the first step in eliminating racism. Our call to reflection must be followed by concrete action. Moving forward, we hope to continue working with our student peers nationwide to identify targets for sustainable institutional change. Opportunities for further action include organizing support within the healthcare community for the End of Racial Profiling Act in the Senate, creating medical student curricula and professional practice guidelines that address interpersonal and systemic manifestations of racism that affect the health of people of color, and joining national efforts to enact a single payer health insurance system.

Although we are trainees entering a hierarchical system, it is imperative that we advocate for change in medicine and other systems that affect the health of our patients and their communities. We are encouraged to see the movement of medical students fighting for racial equity in health care grow and intend to continue this work by building on students' activism and ideas. We look forward to collaborating with allies in other healthcare fields, including public health, nursing, and medical anthropology, to build a more equitable healthcare system and to support community-based efforts to promote racial justice. We hope that, as we expand our biomedical knowledge, we will also develop our humanity and solidarity, and that we will ultimately serve in a healthcare system and in a country that promotes the health and wellbeing of all of our patients.

\section{ACKNOWLEDGMENTS}

The White Coats for Black Lives National Working Group is further comprised of: Charlotte Austin, Elorm Avakame, Joniqua Ceasar, Georgia Himmelstein, Julia Jeffries, Giselle Lynch, Ezekiel Richardson, and Jennifer Tsai. This working group would like to further acknowledge all student participants and supporters of the White Coats for Black Lives student movement. 
Funding Sources. N.B. was supported by R25MD006832 from the National Institute on Minority Health and Health Disparities.

Financial Disclosure Statement. The authors have no financial relationships relevant to this article to disclose. 